\title{
Educating students and future researchers about academic misconduct and questionable collaboration practices
}

\author{
Thomas Edward Gladwin(D)
}

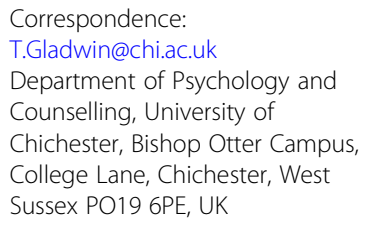

\begin{abstract}
Academic education largely concerns knowledge and skills. Where there is attention to ethics, this tends to focus on study-related misconduct such as plagiarising assignments and, more recently, methodological misconduct. The current paper argues that it is also essential to teach students about social misconduct in science, with a focus on questionable collaboration practices. First, this would increase future early career researchers' ability to succeed and avoid academic snares. Enhancing this ability would appear to be an ethical responsibility going hand-in-hand with our attempts at endowing students with skills that we know could be exploited. Second, such teaching would establish authoritative norms about collaborative practices that are and are not acceptable. This would help to adjust scientific attitudes in next generations of graduates, to the benefit of both themselves and science. Teaching on science-specific social misconduct would also naturally tie in with addressing general forms of antisocial conduct which also occur in academia, such as bullying or sexual harassment. The paper provides a framework for defining and recognizing questionable collaboration practices, and for how to provide students with the attitudes, concepts and skills necessary to protect themselves as they enter the reality of the academic arena.
\end{abstract}

Keywords: Academic integrity, Misconduct, Collaboration, Education, Questionable research practices

\section{The impact of research misconduct on students}

Attention is commonly given to academic misconduct in the context of students' studies, as commonly reflected in "misconduct" sections of typical universities' handbooks. This kind of misconduct has received recent research attention. For instance, students may have others do their work for them and commit plagiarism, or otherwise attempt to acquire undeserved credit. When paid for, this is termed "contract cheating" (Clarke \& Lancaster, 2013) and has been reported to be increasing, with up to around $15 \%$ of students likely to have used this method (Newton, 2018). Such directly study-related misconduct is clearly an important issue. However, misconduct and questionable practices in academic research, rather than in the student experience directly, can also negatively affect students, in three broad ways. First, unethical research negatively affects scientific culture (Engel, 2015) and ultimately weakens the quality of the scientific literature, with authors suggesting unjustified levels of evidence for claims,

(c) The Author(s). 2018 Open Access This article is distributed under the terms of the Creative Commons Attribution 4.0 International License (http://creativecommons.org/licenses/by/4.0/), which permits unrestricted use, distribution, and reproduction in any medium, provided you give appropriate credit to the original author(s) and the source, provide a link to the Creative Commons license, and indicate if changes were made. 
sometimes termed "hyping" (Martin, 2016). This inherently weakens the value of students' education as they will likely be learning material that is at least partly incorrect. Further, the reputation of the students' field will be negatively affected, as in the replication crisis in psychology (Ioannidis, 2005; Murayama et al., 2013; Wagenmakers et al., 2012), and unreliable knowledge will also potentially affect those students' future ability to perform to a high or even safe standard. Second, many students will observe unethical research-related behaviour in some way. For example, researchers known to have bad reputations may be seen to be highly successful at acquiring funding; professors may joke about torturing data until it confesses (Simmons et al., 2011); there may be examples of bullying, e.g., by PIs or professors, being accepted for extended periods of time (Cassell, 2011; McKay et al., 2008); researchers could express or demonstrate plagiarism in its myriad forms beyond just word-for-word copying (Martin, 1994, 2016), including by claiming too much credit for students' work (Martin, 2013); and so on. Students exposed to such experiences are learning that such behaviour is, at least, not inimical to success in academia, and perhaps it even appears to be necessary. This is teaching the ethical opposite of what an academic education should aim to provide honestly, transparency, collegiality, the willingness to actually do the hard work of science, and so forth. Finally, some students are future junior researchers, especially $\mathrm{PhD}$ students. They could therefore be negatively affected by academic misconduct directly. Are they being adequately prepared for this encounter?

The aim of the current paper is to argue that academic education needs to provide students with explicit, authoritative, and unambiguous information and training on "social" as well as study-related and methodological academic misconduct.

\section{Research-related academic misconduct and collaboration}

In recent years, concern for questionable research practices (John et al., 2012) has risen, hand in hand with the so-called replication crisis in psychology (Murayama et al., 2013; Simmons et al., 2011). This has focused on statistical issues. Take, for instance, $p$-hacking, the practice of varying methodological choices and picking the one that gives the best outcome, generally being the lowest $p$-value (although the exact same problem would occur for any alternative statistical outcome, e.g., the Bayes factor, that can be manipulated). This has been successfully widely branded as misconduct, and disapproval of $p$-hacking has become a norm that can be communicated to students as part of their methodology and statistics classes. There are also non-statistical forms of misconduct, on which some light is already being shined, related to general social interactions. Bullying, for instance, was long tolerated - the "star" researcher, the "top talent", sometimes being given leeway in their mistreatment of students or post-docs (Cassell, 2011; Chu, 2018; McKay et al., 2008). The bullying problem has reached mainstream media, in articles such as "We need a bigger conversation about bullying in academia" (Anonymous, 2018b). Sexual harassment in academia has also long been recognized (Fitzgerald et al., 1988; van Roosmalen and McDaniel, 1999) and remains an issue, also being brought to light in publications outside academia such as the article "As a young academic, I was repeatedly sexually harassed at conferences" (Anonymous, 2018a).

There is however a further, subtler but nevertheless harmful, form of academic social misconduct, here termed questionable collaboration practices (QCP). The term QCP is intended to cover a broad range of related forms of intellectual exploitation and 
plagiarism. Rather than involving statistical misconduct or general antisocial behaviour, QCP is misconduct specifically related to the social aspect of doing scientific research, for which the overall term "collaboration" is used here. Formulations of general ethics concerning collaboration have been articulated in, e.g., the Montreal Statement on Research Integrity in Cross-Boundary Research Collaborations (developed as part of the 3rd World Conference on Research Integrity, 2013) and the Singapore Statement on Research Integrity (Resnik \& Shamoo, 2011), but issues surrounding intellectual exploitation do not appear to be widely recognized as requiring specific attention and labelling (Martin, 2013, 2016).

Science at every level involves collaboration: all researchers build on others' work and require the often somewhat selfless contribution of peers - from laboratory know-how passed on via experienced technicians or researchers to voluntary peer-review and editing to multi-centre, years-long research projects. This cooperative, trust-based fabric stands in sharp contrast to competitive, winner-take-all academic systems (Van den Berghe, 1970; Woolston, 2014; Xie, 2014). An individual playing the academic game is incentivized to improve their chances to survive and win in terms of their career, via whichever metrics the score is kept; and this is inherently to the detriment of the chances of others. That some academics in some sense cheat at the game has been described as a commonplace observation: "The point that merit sometimes takes a backseat to more unpalatable considerations in advancing academic careers is hardly an original observation. Indeed, made merely as an offhand remark, it would seem little more than a commonplace. It is implied when someone is referred to as a sycophant, intriguer, or poseur" (Lewis, 1975). One way to win the game via cheating is to exploit others, i.e., QCP. The idea of the wily hustler, manipulative organizer, or dominant group leader exploiting talented but vulnerable students or researchers is likely not unfamiliar to the reader. While anecdotal evidence of such interactions abounds, hard data seem more difficult to come by. This could be related to lack of recognition or labelling of the behaviour as undesirable - once the problem is acknowledged, research efforts could be devoted to its prevalence and consequences. Clearly, even if exploitative strategies are common and effective, they should be normatively undesirable, being for one thing a form of plagiarism - one person is aiming to unfairly profit from, and ultimately get credit for, the work or abilities of another. The ability of the current academic system to protect itself and students from misconduct will realistically always be limited. Educators need to respond adequately to this reality. To do so, students need to be taught strong norms concerning the concept of QCP and exploitation, presented as a matter of course during their studies in the same way that they are, for instance, made aware of $p$-hacking being unacceptable. Such norms obviously may not fit all academics' agenda. As will be clear, there is an uncomfortable friction between anti-exploitation norms and the winner-take-all system and the associated widespread use of $(\mathrm{PhD})$ students and post-docs in a hierarchical lab structure. Nevertheless, it appears difficult to deny that at the least, students need guidance on what is and isn't appropriate in terms of working with or for other people. This is a special responsibility for educators who could be, as it were, cursing students with competence, that is: We want to make students good researchers with strong skills - but that makes them targets for exploitation as well. Teaching research skills must therefore go hand in hand with teaching the ethics of collaboration and social self-defense skills. 


\section{Defining and recognizing questionable collaboration practices}

QCP can be defined in contrast to three positive principles of an ideal academic collaboration: consent, contribution, and credit. Together these principles represent what could be termed ownership of personal scientific competence: first, that individuals have the right to spend their time working towards their own scientific goals; second, that they may select only collaborators they believe will make a significant additional contribution to their aims; and third, that they have the right for all contributions to be accurately credited. Note that consent can, of course, be given altruistically and freely to support a collaborative project or peers can be a scientific goal. The principle only claims that this should be voluntary. This is necessary to avoid a tyranny of the incompetent in which, rather than the norm being to personally develop the scientific competence one requires, scientific support can be demanded at the cost of others to fulfil one's own personal ambitions. Given these principles, it is unethical to be pressured or induced to work to the personal advantage of other researchers, to disproportionally profit from others, or to misrepresent the distribution of real contributions. QCP entails any form of this kind of theft of competence. It is not only unfair to the student or researcher as an individual but also harms the academic system by forcing positive, trust-based attitudes to become more defensive and incorrectly assigning credit and therefore benefits and, ultimately, power.

On the other hand, of course, collaboration is often necessary and positive. In the ideal collaboration, each person makes a real contribution that is both necessary and reflected in the eventual distribution of credit; this could involve either sharing work or contributing to different parts of a study. Awareness of QCP will hopefully help students and researchers identify and focus on collaborations that are in fact mutually beneficial and fair. Evaluating contributions will always be a matter of judgment, but as a prerequisite to that the issues of QCP and real contributions must be recognized as important and, in particular, ethically appropriate to critically consider. Thus, an important element of training students to navigate QCP should involve thinking critically about what "real" contributions entail. This could build on good authorship practices (Baskin \& Gross, 2011; Bavdekar, 2012; van Loon, 1997), but the first aim should simply be to start an explicit discussion that lets students reflect on typical cases. For instance, an idea or research question could be considered a real contribution only if it is an individual intellectual step beyond what can be simply taken from the existing literature with minimal effort. Taking an organizing role is of questionable value if other participants could in fact have organized themselves perfectly well. There are middle-man contributions that arguably should not be considered worthy of scientific credit - it can be questioned whether or not bringing relevant people into contact with each other involves collegiality rather than collaboration. Providing access to resource is a difficult case - it may be worth it to a requesting researcher to buy such access with a collaboration and ultimate co-authorship, but is it ethical? Finally, it should always be very critically considered what real contribution individuals make to studies of which the research question is closely linked to specialist techniques, who themselves lack the real-life knowledge and ability to perform that kind of research.

QCP applies to student research projects and research jobs as well as peer-to-peer collaborations not directly linked to study or employment. Although the freedom to decline research is of course lost to some extent within employment or 
apprenticeship-type roles, it seems that this should not affect the ethical duty to, to the greatest extent possible, allow the choice to select such a role to be based on informed consent and to avoid all forms of plagiarism and competence theft. Supervisor exploitation has been previously noted as a form of QCP, and typical tactics, such as devaluation of the student's contribution, have been helpfully identified and could be taught to students and staff (Martin, 2013). Once ethical norms are established the relevant ethics of employers, labs and departments can also more easily become part of formal and informal discussions that can help steer individuals towards beneficial experiences. In the context of university students, this may enhance student experience and the probability of good longer-term education outcomes. While the focus of the current paper is on students, it should be noted that other individuals may well be vulnerable to QCP, including but not limited to junior staff.

\section{Teaching and changing attitudes on QCP}

Currently, teaching students about QCP and how to defend themselves from it appears to occur in an ad-hoc fashion at best. This section uses the Theory of Planned Behaviour (Ajzen, 1988; Orbeil et al., 1997) as a framework to provide some basic principles for conveying ethical and critical attitudes concerning QCP and exploitative practices. In the theory, intentions to behave a certain way are determined by (1) social norms, (2) perceived behavioural control, and (3) personal attitudes. These aspects tie directly in to education. First, concerning social norms, simply presenting ethical rules and guidelines as part of the curriculum establishes that they have the approval of the university, providing normative authority. A secondary consequence of such teaching is that once QCP issues are officially taught to students, it would be highly and conspicuously hypocritical for department members to commit misconduct. This teaching could thus conceivably benefit the academic environment. One concrete possibility would be to develop codes of conduct reflecting ethical norms on exploitation, to be signed by supervisors and students. Second, perceived behavioural control in navigating pressures involving QCP is supported by the social norms. Students need to be confident they have the right to decline anything they perceive as exploitative or simply insufficiently equitable in terms of contribution. Perceived control could also be enhanced via teaching methods such as role-playing (Karatay \& Gürarslan Baş, 2017). Perceived and actual control would also be increased simply by learning about common forms of misconduct and becoming a critical evaluator of suggested contributions or "tokens" of expertise. For instance, students who have learned about the issue of ghost authorship (Baskin \& Gross, 2011; Bavdekar, 2012; LaFollette, 1992; van Loon, 1997) may be more likely to look beyond superficial credentials. Some strategies that could help students increase their control have been provided in previous work, such as careful note-keeping and minuting of meetings (Martin, 2013). Agreements should be made early and in writing, shared for confirmation over email. Learning about QCP could help students think more critically about which projects they accept and which future jobs they take. For instance, potential $\mathrm{PhD}$ students need to learn to critically evaluate potential supervisors by making sure they talk to multiple possible supervisors as well as current and previous students, if possible, and check the publication records of previous students. This is of course a difficult task, but at least some awareness and a critical attitude will serve students well, and hopefully they will have disinterested lecturers 
they can approach for mentorship and tips. Finally, the individual's attitudes and values will play a role. Does the individual care about the corrosive impact that QCP have on science? This can only be taught to a certain extent. However, simple self-interest is sufficient to motivate an avoidance of exploitation, which subsequently benefits both the individual and the academic system.

\section{Conclusion}

Academia is a complex system, involving many incentives that can lead to undesirable conduct. Part of the responsibility of educators is to teach students to navigate that system. In particular if we give students exploitable skills, we can foresee that some of them will indeed be exploited. Given the winner-take-all mechanisms common in science, such individuals may not recover from this, and it seems at least possible that unfair practices may even be unhealthy, contributing to the high incidence of serious mental health problems in academia, with particularly concerning rates in $\mathrm{PhD}$ students (Evans et al., 2018; Levecque et al., 2017). Therefore, educators need to train students to recognize QCP and be able to conceptualize and verbalize any concerns appropriately, if only to themselves. Students need to be very comfortable with critically considering whether a collaboration is or is not OK. Further, teachers in the role of representatives of their university and to an extent the scientific world need to clearly identify and acknowledge QCP as a form of misconduct just as unacceptable as plagiarism in writing, bullying, sexual harassment or $p$-hacking. This is not to suggest that education alone will be able to solve the issues of QCP, general social misconduct and cheating in academia. Such problems are persistent and arguably even incentivized by some aspects of academic systems of funding, employment and career progression. Even well-intended metrics will only imperfectly reward good science rather than unethical strategies such as hyping, exploitation or plagiarism, thereby running the risk not only of victimization of individuals but also the spread of attitudes and strategies damaging to institutes and scientific fields (Engel, 2015). It is therefore an important responsibility of academic leadership and policy makers to identify and censure, rather than reward, questionable practices. Education may, however, be an essential factor in changing the prevalence of attitudes and behaviours in future generations of scientists, and thereby at least in some cases change the expected payoff of academic corruption.

Abbreviation

QCP: Questionable Collaboration Practices

Acknowledgements

There are no acknowledgements.

Funding

There was no funding for the current study.

Availability of data and materials

The paper did not involve data or material. 
Competing interests

The author reports no competing interests.

\section{Publisher's Note}

Springer Nature remains neutral with regard to jurisdictional claims in published maps and institutional affiliations.

\section{Received: 4 September 2018 Accepted: 9 November 2018}

Published online: 22 November 2018

\section{References}

Ajzen I (1988) Attitudes, personality, and behavior. Open University Press, Maidenhead.

Anonymous. (2018a). As a young academic, I was repeatedly sexually harassed at conferences. The Guardian. Retrieved from https://www.theguardian.com/higher-education-network/2017/dec/01/as-a-young-academic-i-was-repeatedly-sexuallyharassed-at-conferences. Accessed 15 Nov 2018.

Anonymous. (2018b). We need a bigger conversation about bullying in academia. The Guardian. Retrieved from https://www. theguardian.com/higher-education-network/2018/jan/26/we-need-a-bigger-conversation-about-bullying-in-academia. Accessed 15 Nov 2018.

Baskin PK, Gross RA (2011) Honorary and ghost authorship. BMJ (Clinical Research Ed) 343:d6223. https:/doi.org/10.1136/BMJ.D6223

Bavdekar SB (2012) Authorship issues. Lung India : Official Organ of Indian Chest Society 29(1):76-80. https://doi.org/10.4103/ 0970-2113.92371

Cassell MA (2011) Bullying in academe: prevalent, significant, and incessant. Contemporary Issues Educ Res 4(5):33-44

Chu, A. L. (2018). I worked with avital Ronell. I believe her accuser. The Chronical of Higher Education. Retrieved from https:// www.chronicle.com/article/l-Worked-With-Avital-Ronell-I/244415

Clarke R, Lancaster T (2013) Commercial aspects of contract cheating. In: Proceedings of the 18th ACM conference on Innovation and technology in computer science education - ITiCSE '13 (p. 219). ACM Press, New York. https://doi.org/10. $1145 / 2462476.2462497$

Engel C (2015) Scientific Disintegrity as a public bad. Perspect Psychol Sci 10(3):361-379. https://doi.org/10.1177/ 1745691615577865

Evans, T. M., Bira, L., Gastelum, J. B., Weiss, L. T., \& Vanderford, N. L. (2018). Evidence for a mental health crisis in graduate education. Nat Biotechnol 2018 36:3, 36(3), 282-284. doi: https://doi.org/10.1038/nbt.4089

Fitzgerald LF, Shullman SL, Bailey N, Richards M, Swecker J, Gold Y et al (1988) The incidence and dimensions of sexual harassment in academia and the workplace. J Vocat Behav 32(2):152-175. https://doi.org/10.1016/0001-8791(88)90012-7

loannidis JPA (2005) Why Most published research findings are false. PLoS Med 2(8):e124. https://doi.org/10.1371/journal. pmed.0020124

John LK, Loewenstein G, Prelec D (2012) Measuring the prevalence of questionable research practices with incentives for truth telling. Psychol Sci 23(5):524-532. https://doi.org/10.1177/0956797611430953

Karatay, G., \& Gürarslan Baş, N. (2017). Effects of role-playing scenarios on the self-efficacy of students in resisting against substance addiction: a pilot study. Inquiry, 54, 46958017720624. doi: https://doi.org/10.1177/0046958017720624

LaFollette MC (1992) Stealing into print: fraud, plagiarism, and misconduct in scientific publishing. University of California Press, Berkeley. https://doi.org/10.1086/230533

Levecque K, Anseel F, De Beuckelaer A, Van der Heyden J, Gisle L (2017) Work organization and mental health problems in PhD students. Res Policy 46(4):868-879. https://doi.org/10.1016/j.respol.2017.02.008

Lewis, L.S (1975). Scaling the ivory tower : merit and its limits in academic careers. Johns Hopkins University Press, Baltimore Martin B (1994) Plagiarism: a misplaced emphasis. J Inf Ethics 3(2):1-19 Retrieved from https://philpapers.org/rec/MARPAM-8 Martin B (2013) Countering supervisor exploitation. J Sch Publ 45(1):74-86. https://doi.org/10.3138/jsp.45-1-004

Martin B (2016) Plagiarism, misrepresentation, and exploitation by established professionals: power and tactics. In: Handbook of academic integrity. Springer Singapore, Singapore, pp 913-927. https://doi.org/10.1007/978-981-287-098-8_75

McKay R, Arnold DH, Fratzl J, Thomas R (2008) Workplace bullying in academia: a Canadian study. Empl Responsibilities Rights J 20(2):77-100. https://doi.org/10.1007/s10672-008-9073-3

Murayama, K., Pekrun, R., \& Fiedler, K. (2013). Research Practices That Can Prevent an Inflation of False-Positive Rates. Personality and Social Psychology Review : An Official Journal of the Society for Personality and Social Psychology, Inc, 1088868313496330-. doi: https://doi.org/10.1177/1088868313496330

Newton PM (2018) How common is commercial contract cheating in higher education and is it increasing? A systematic review. Frontiers Educ 3(67). https://doi.org/10.3389/feduc.2018.00067

Orbeil S, Hodgkins S, Sheeran P (1997) Implementation intentions and the theory of planned behavior. Personal Soc Psychol Bull 23(9):945-954. https://doi.org/10.1177/0146167297239004

Resnik DB, Shamoo AE (2011) The Singapore statement on research integrity. Account Res 18(2):71-75. https://doi.org/10. 1080/08989621.2011.557296

Simmons JP, Nelson LD, Simonsohn U (2011) False-positive psychology: undisclosed flexibility in data collection and analysis allows presenting anything as significant. Psychol Sci 22(11):1359-1366. https://doi.org/10.1177/0956797611417632

Van den Berghe, P. L. (1970). Academic gamesmanship; how to make a Ph. D. pay. Abelard-Schuman

van Loon AJ (1997) Pseudo-authorship. Nature 389(6646):11-11. https://doi.org/10.1038/37855

van Roosmalen E, McDaniel SA (1999) Sexual harassment in academia: a Hazard to Women's health. Women Health 28(2):3354. https://doi.org/10.1300/J013v28n02_03

Wagenmakers E-J, Wetzels R, Borsboom D, van der Maas HLJ, Kievit RA (2012) An agenda for purely confirmatory research. Perspect Psychol Sci 7(6):632-638. https://doi.org/10.1177/1745691612463078

Woolston C (2014) Winner takes all in science. Nature 510(7503):11-11. https://doi.org/10.1038/510011e

Xie Y (2014) "Undemocracy": inequalities in science. Science 344(6186):809-810. https://doi.org/10.1126/science.1252743 